\title{
Modelling hillslope sediment transport rate on grassland
}

\author{
Dongdong Wang ${ }^{1}$, Fen Liu ${ }^{1}$, Ningning Song ${ }^{2}$, Yan Tang ${ }^{3}$, and Zaijian Yuan ${ }^{4}$ \\ ${ }^{1}$ College of Resources, Environment and Planning, Dezhou University \\ ${ }^{2}$ College of Resources, Environment and Planning, \\ ${ }^{3}$ tate Key Laboratory of Soil Erosion and Dryland Farming on the Loess Plateau, \\ ${ }^{4}$ Guangdong Key Laboratory of Integrated Agro-environmental Pollution Control and \\ Management
}

June 22, 2020

\begin{abstract}
Few data are available for estimating the sediment transport rate on a steep slope of grass with different covers. In this study, the artificial simulated rainfall test is used to investigate how rainfall intensity, slope and cover affect the sediment transport rate. Simultaneously, the study establishes a model for the sediment transport rate using shear stress, stream power, unit stream power and unit energy on steep grassland slopes. Results show that the sediment transport rate decreases as the vegetation cover increases, as described by linear or logarithmic equations under different rainfall intensities or slopes. The sediment transport rate increases as an exponential function equation with rainfall intensity, slope and cover with a Nash-Sutcliffe model efficiency (NSE) value of 0.864 . The effects of slope steepness are stronger than the effects of rainfall intensity and cover. Regression analyses show that the sediment transport rate can be predicted from the power function equations of shear stress, stream power and unit energy. In addition, the sediment transport rate can be fit to unit stream power with linear equation $(\mathrm{NSE}=0.840)$. Further analysis shows that the sediment transport rate is best modelled by a power function equation that includes three factors, i.e. rainfall intensity, vegetation cover and slope.The measurements and calculations of the sediment transport rate, the calculations of the surface roughness and characteristic considerations of the vegetation for sheet flow should be explored in future research, which are important in improving experimental accuracy and sediment transport rate modell
\end{abstract}

\section{Hosted file}

Modelling hillslope sediment transport rate on grassland \begin\{CJK\}\{UTF8\}\{gbsn\}. \end\{CJK\}\selectlangua } available at https://authorea.com/users/333569/articles/461654-modelling-hillslope-sedimenttransport-rate-on-grassland

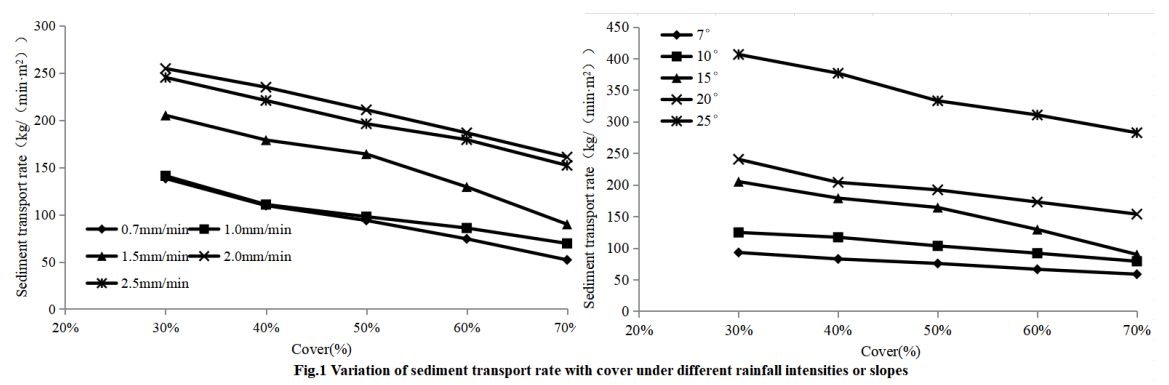



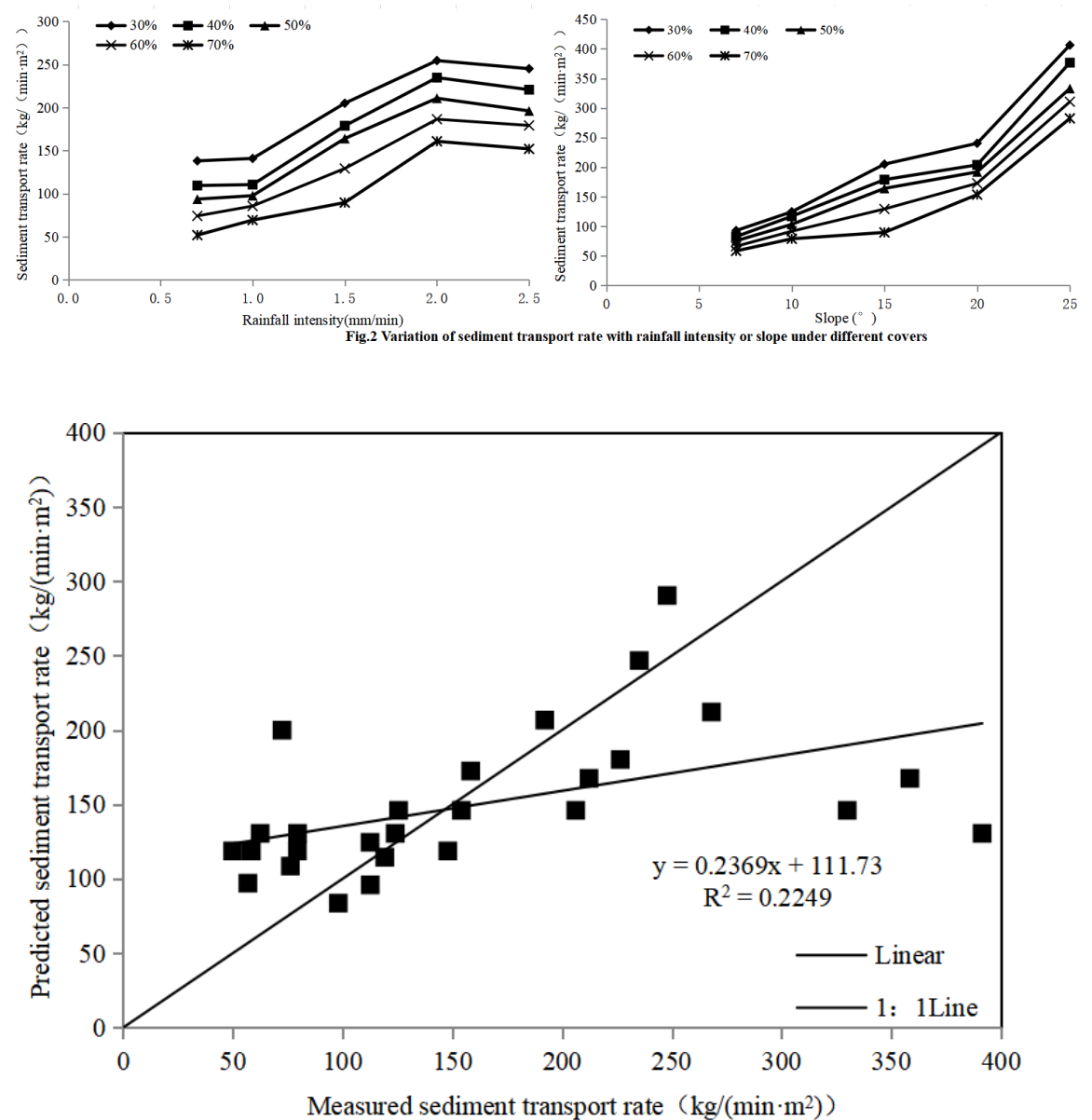

Fig.3 Measured vs. predicted sediment transport rate (using the model: $S T=70.882 I^{0.731} C^{-0.615}$ )

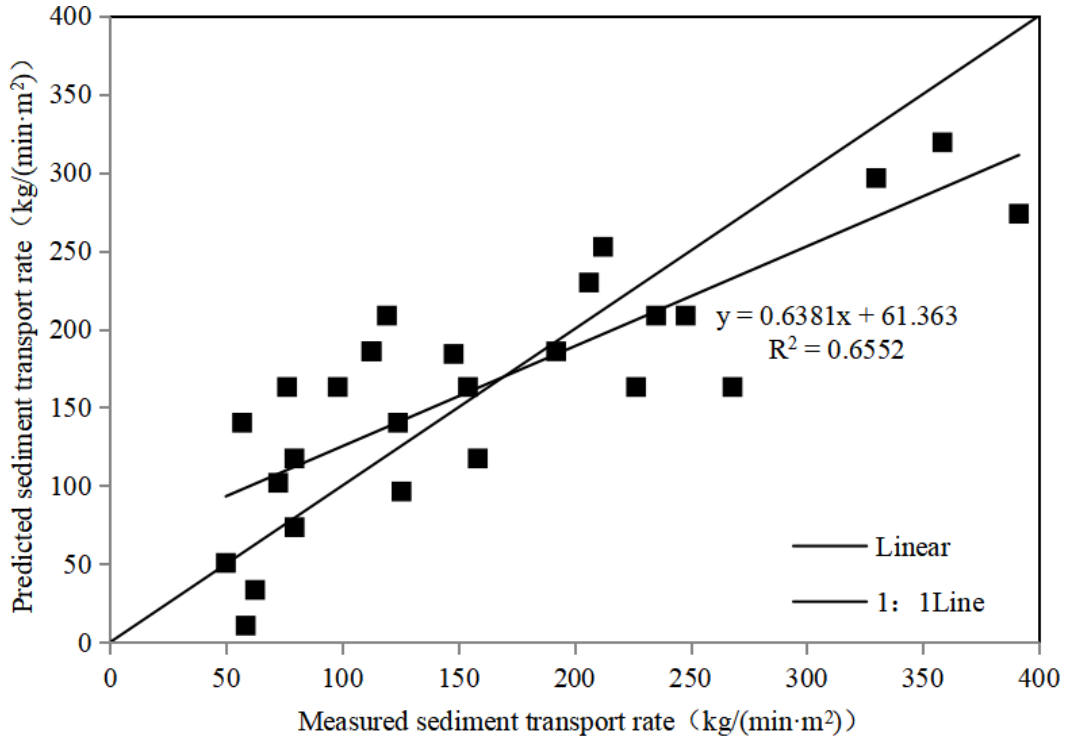

Fig.4 Measured vs. predicted sediment transport rate (using the model: $\mathrm{ST}=76.857+13.346 \mathrm{~S}-$ 228.027 C) 


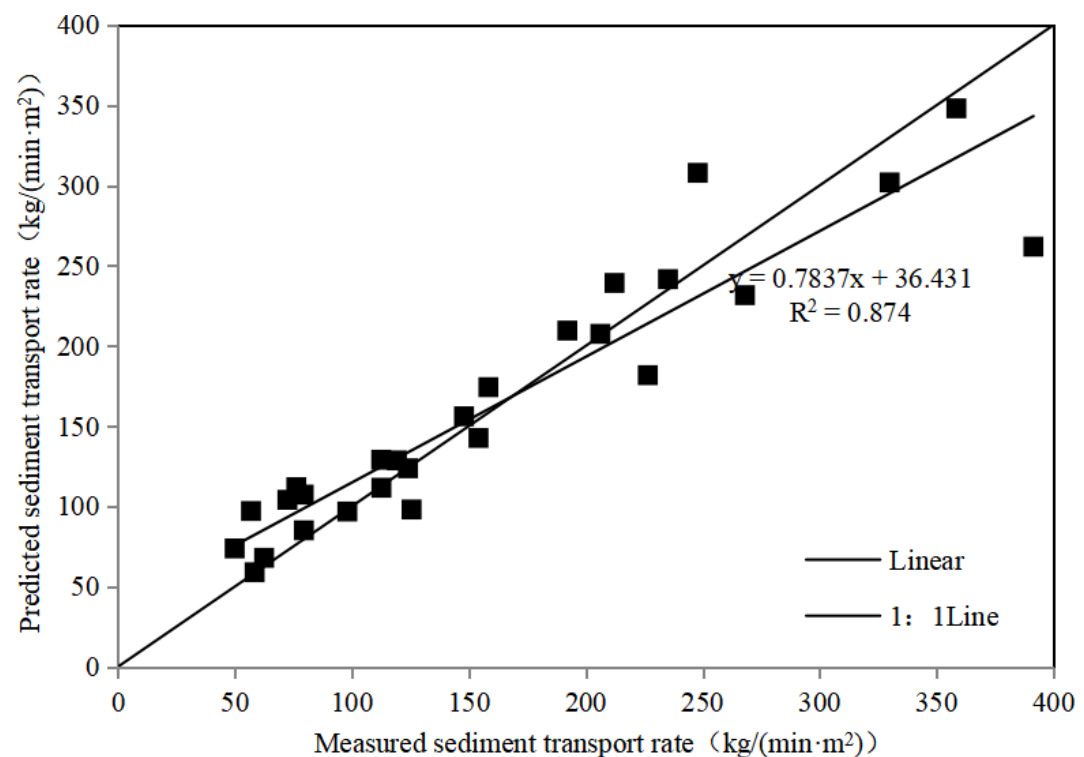

Fig.5 Measured vs. predicted sediment transport rate (using the $\operatorname{model}: \mathrm{ST}=45.571 \mathrm{e}^{0.485 \mathrm{I}^{+}}$ $0.075 \mathrm{~S}-1.423 \mathrm{C}$ )

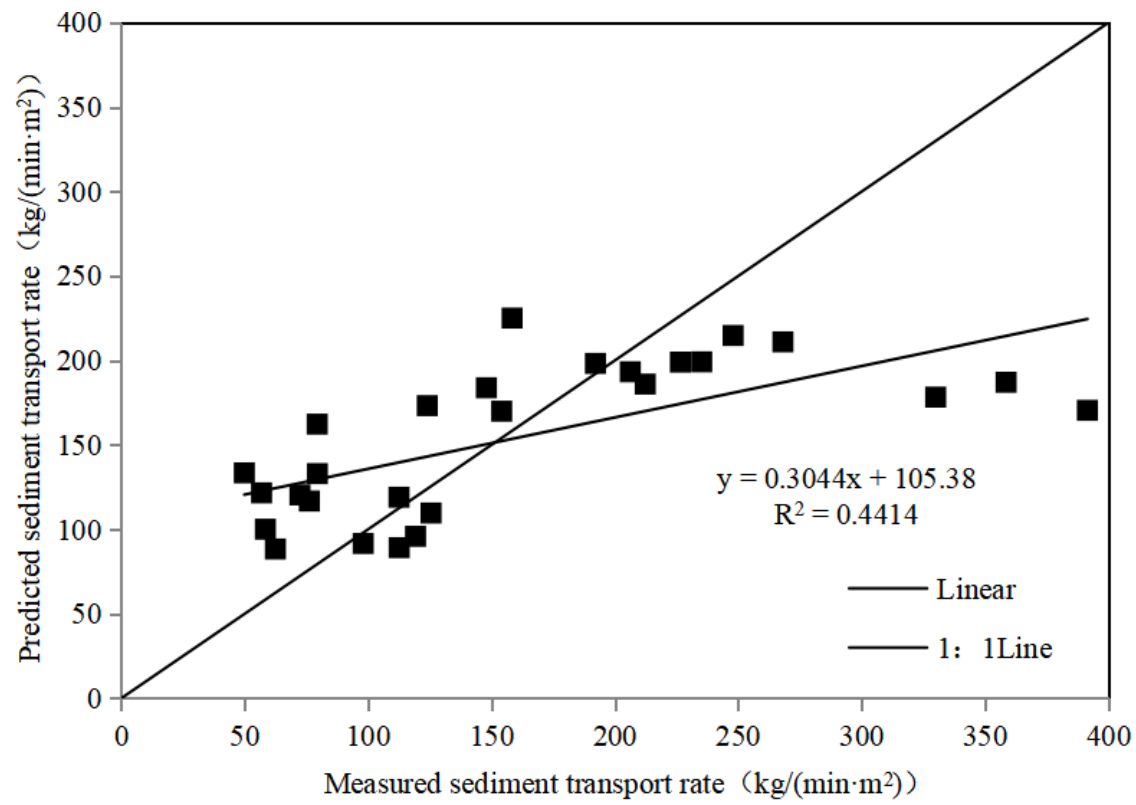

Fig.6 Measured vs. predicted sediment transport rate (using the model: $S T=488.188 \tau^{0.884}$ ) 


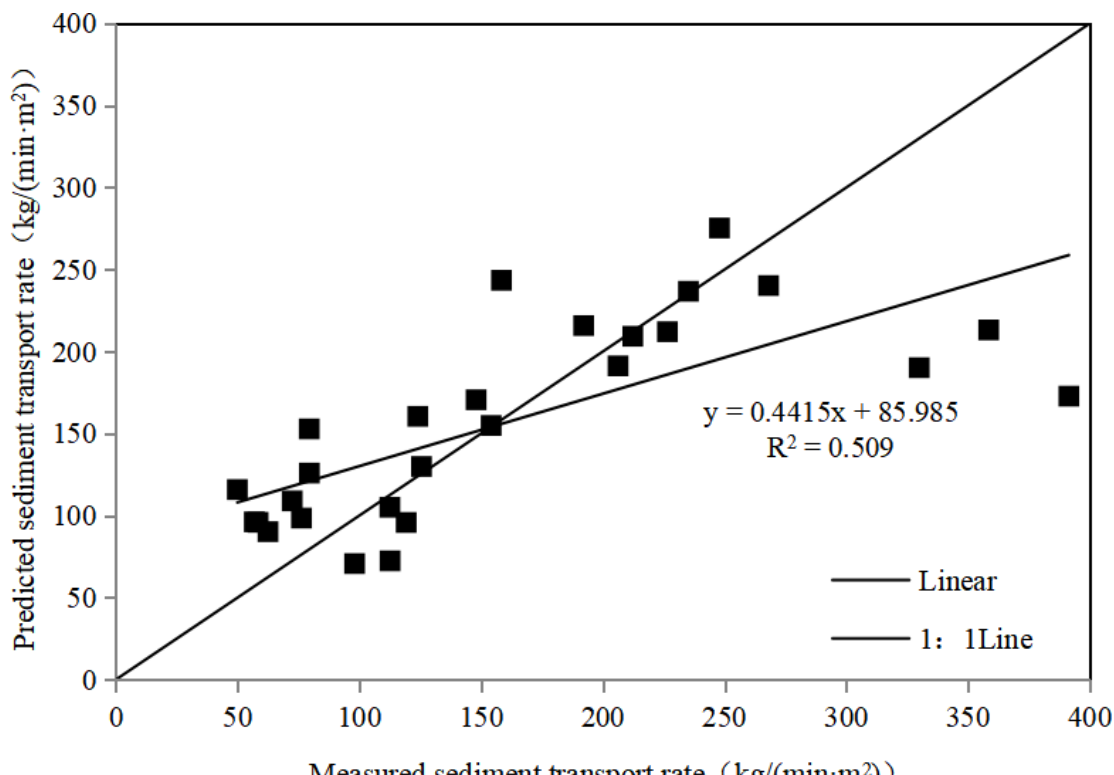

Fig.7 Measured vs. predicted sediment transport rate (using the model: $S T=2630.089 \omega^{0.789}$ )

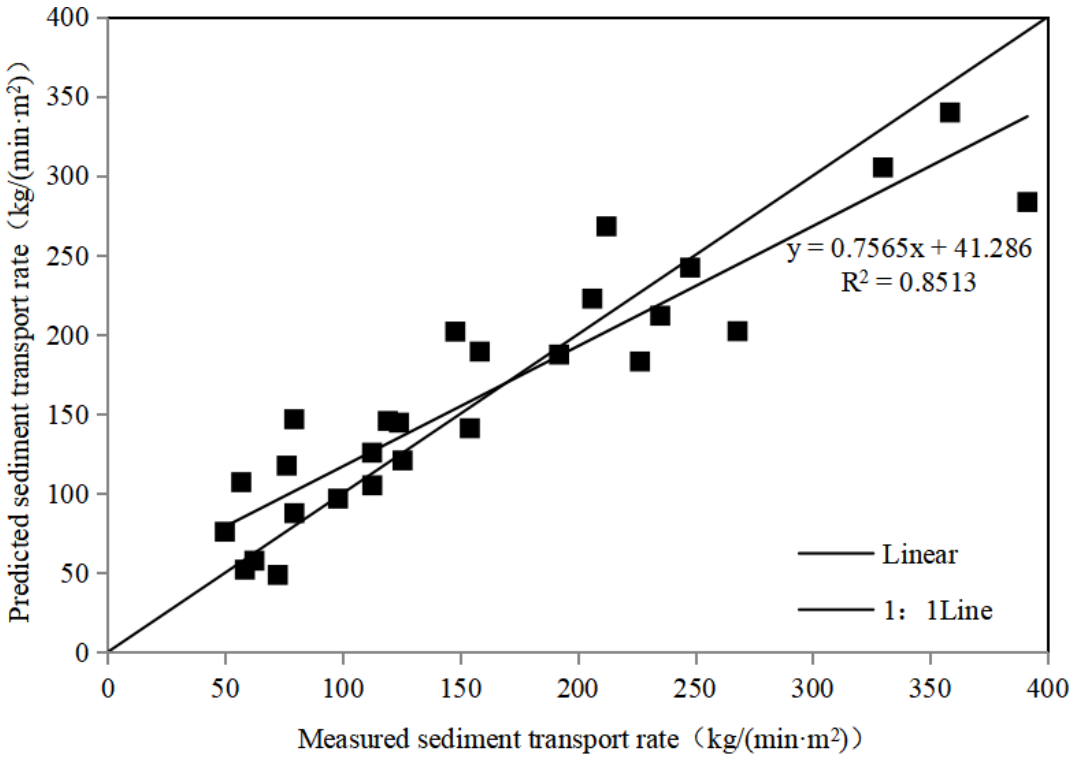

Fig.8 Measured vs. predicted sediment transport rate (using the model: $\mathrm{ST}=\mathbf{7 0 3 3 . 5 1} \mathrm{U}-\mathbf{2 5 . 3 3 2}$ ) 


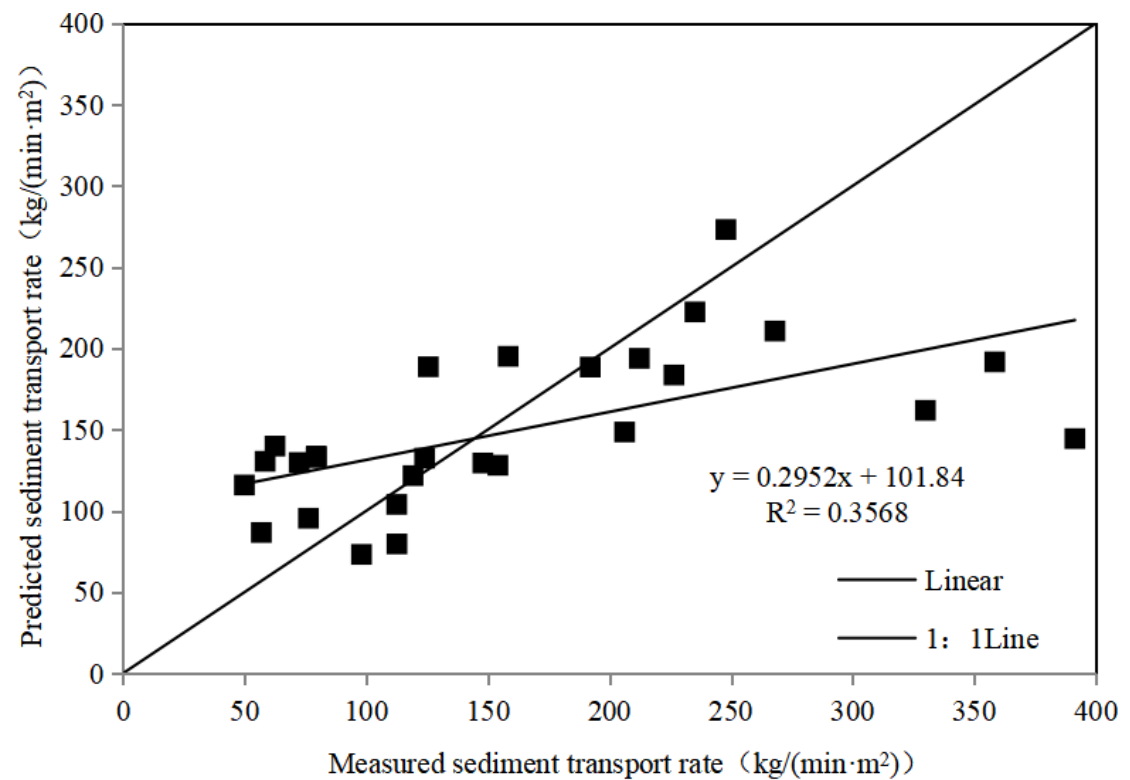

Fig.9 Measured vs. predicted sediment transport rate (using the model: $S T=1696.159 E^{0.887}$ ) 